\title{
ATROPHIC POLYCHONDRITIS WITH THE REPORT OF A CASE
}

\author{
BY \\ H. RHYS DAVIES AND A. R. KELSALL \\ From the West Herts Hospital, Hemel Hempstead, Herts
}

During recent years a number of patients have been described in whom degeneration of cartilage in the ears, nose, respiratory tract, and thoracic cage has been associated with polyarthritis and sometimes also with iritis or episcleritis. The first recorded case appears to be that of Jaksch-Wartenhorst (1923) in Prague: a man aged 32 years became ill with multiple arthritis and fever and this was followed by swelling of both external ears, proceeding to shrinkage and deformity, with partial stenosis of the external auditory canals, deafness, and tinnitus; the nasal cartilage collapsed, producing a saddlenose deformity; the epiglottis became shortened, thick, and nodular; pain and tenderness developed in the costochondral junctions and xiphoid process. Jaksch-Wartenhorst considered that this was a hitherto undescribed degenerative disorder of cartilage and named it polychondropathia.

Von Meyenburg (1936), in Zurich, briefly reported a second case and a full account of the same patient was published by Altherr (1936); neither author was aware of Jaksch-Wartenhorst's earlier paper and they described the condition as chondromalacia. This patient was a boy aged 14 years, who died 10 months after the onset of an illness in which a migrating polyarthritis involving the large joints was accompanied by softening of cartilage in the ears, nose, larynx, trachea, and chest wall. Tracheotomy was required to relieve respiratory obstruction. At autopsy, miliary tuberculosis was found with a primary tuberculous complex in the right lung, but the changes in the joints and cartilages were not tuberculous and appeared to be due to a mixture of degenerative and inflammatory processes. Histological evidence of rheumatic myocarditis was also found.

Gordon, Perlman, and Shechter (1948), in the United States, reported a third case, again without knowledge of the preceding publications. An American Negress aged 34 years developed arthritis of the knees and ankles, associated with fever, swelling of the ears, hoarseness, and tenderness over the sternum and chest wall. This patient also required tracheotomy, and biopsy specimens of cartilage showed a mixture of degenerative and inflammatory changes. A further feature was bilateral iritis and conjunctivitis.

A fourth case, with severe ocular complications leading to blindness, was described by Hilding (1952). In this patient, a woman aged 61 years, progressive polyarthritis was associated with deepening of the voice, deformity of the ears and nose, and softening of the costal cartilages. Harders (1954) recorded a further case, a boy aged 16 years, who also needed tracheotomy and in whom the softening of cartilage involved the nose, ribs, larynx, and trachea, with arthritis and episcleritis. Harders recognized that the disease was similar to that described by Von Meyenburg (1936) and Altherr (1936) and that reported by Gordon, Perlman, and Shechter (1948). Similar cases were published by Rogers and Lansbury (1955), and Bober and Czarniecki (1955), both patients being women, aged 61 and 41 years respectively. Each had ocular manifestations and the patient described by Bober and Czarniecki also required tracheotomy. Harders (1956), in a further publication, mentioned three other cases, diagnosed since his earlier paper, but did not give details.

Another typical case was described by Harwood (1958): a man aged 35 years died of respiratory obstruction. Another patient, a woman aged 63 years, was reported by Klatskin and Katzenstein (1958): this patient also died of respiratory infection secondary to chronic respiratory obstruction. Bean, Drevets, and Chapman (1958) reviewed the syndrome and added yet another case, a woman aged 58 years. Two further cases, a man aged 33 years and a woman aged 29 years, were reported by Pearson, Kline, and Newcomer (1960) in a second full review of the syndrome, in which for the first time JakschWartenhorst's original case was quoted. At the Sixth International Congress of Internal Medicine, Bean (1960) reported briefly the details of six additional unpublished cases and Gill (1960) reported another case. 
It thus appears that less than twenty examples of this remarkable syndrome have been published to date, and so far as we are aware no case has previously been reported from Great Britain. We present in this paper details of a typical case which has been observed by us over the past 5 years, though we only recently became aware of previously reported cases. To anyone familiar with the syndrome diagnosis would present no difficulty, and if its existence becomes more generally known it may well be found to be less rare than now appears.

There is, as yet, no agreement on nomenclature: the terms so far used have included polychondropathia (Jaksch-Wartenhorst, 1923), chondromalacia (Von Meyenburg, 1936; Altherr, 1936); panchondritis (Harders, 1954); polychondritis chronica atrophicans (Bober and Czarniecki, 1955); chronic atrophic polychondritis (Bean, Drevets, and Chapman, 1958); relapsing polychondritis (Pearson, Kline, and Newcomer, 1960). Perhaps atrophic polychondritis describes the essential features of the disorder most accurately and briefly.

\section{Case Report}

A married woman aged 64 years was first seen on March 22, 1955, by Mr. W. D. Doey, consultant ear, nose, and throat surgeon to the West Herts Hospital. She complained of difficulty in swallowing and of a sense of constriction in the throat, these symptoms having started one week previously. She was found to have congestion and oedema of the arytenoids and aryepiglottic folds; the vocal cords appeared healthy, but their approximation on phonation seemed to be hampered by the soft tissue swelling; in addition, she had otitis externa with soft swelling of both external auditory meati and some oedema of the skin covering the auricles; the auricular cartilage appeared softer than normal.

She was admitted to the West Herts Hospital on March 24, 1955, and was found to have a persistent irregular fever up to $101^{\circ} \mathrm{F}$. The oedema of the arytenoids and aryepiglottic folds rapidly subsided: her nose showed some deflection of the septum to the left and crusting on the left side, but no pus, and $x$ rays of the chest and nasal sinuses showed no definite abnormality. There was some discomfort on swallowing and pooling of mucus in the pyriform fossa, but a barium swallow on April 18 showed no abnormality in the oesophagus. Examination of the blood on April 12 showed haemoglobin $10 \cdot 3$ g. $/ 100 \mathrm{ml}$.; packed cell volume 33 per cent.; mean corpuscular haemoglobin concentration 31 per cent; leucocytes $7,000 / \mathrm{c}$.mm. (neutrophils 6,076 , eosinophils 28 , basopnils 28 , lymphocytes 728 , monocytes 140 ); erythrocyte sedimentation rate $59 \mathrm{~mm}$./hr (Wintrobe).

Because of the persistent pyrexia, she was seen by one of us (A.R.K.) on April 13. Apart from the swelling of the ears, the only abnormal findings were those in the respiratory system; movement and air entry were diminished at the left lung base and she was producing $\underset{\widehat{\sigma}}{\overparen{2}}$ mucopurulent sputum. A second $x$ ray of the chest (April 14) showed congestive changes at the bases and the sputum yielded a heavy growth of Staph. aureus. A catheter specimen of urine was sterile and the blood. Wassermann reaction was negative. Blood culture was $\overrightarrow{\bar{N}}$ sterile and serum agglutination titres to $S$. typhi, $S . \frac{\overrightarrow{0}}{0}$ paratyphi A, B, and C, S. typhimurium and Brucella abortus were negative. On April 21 she developed $\frac{\bar{\sigma}}{\bar{c}}$ tenderness in both calves and oedema of the legs and was $\frac{\pi}{\sigma}$ thought to have thrombophlebitis: treatment was started $\propto$ with Dicoumarin and aureomycin (to which the staphylo- ڤ coccus in the sputum was sensitive), but the pyrexiacontinued and after a week the aureomycin was stopped,. though treatment with Dicoumarin was continued for $\overrightarrow{\vec{\omega}}$ 7 weeks. Further laboratory studies at this time, aimed $\omega_{\sigma}^{\omega}$ at elucidating the cause of the persistent pyrexia, served only to confuse the diagnosis. A second catheter $\widehat{a}$ specimen of urine (April 25) yielded a heavy growth of 0 B. coli sensitive to streptomycin, but a course of strepto-i mycin for 4 days produced no effect on the temperature. $\vec{\infty}$ Cystoscopy and retrograde pyelography (May 11) showed no abnormality, the ureteric urine specimens을 being sterile. A further blood count (April 28) showed a fall in haemoglobin to $9 \mathrm{~g} . / 100 \mathrm{ml}$, , the leucocytec count being $6,500 /$ c.mm. with a normal differential count, and the erythrocyte sedimentation rate $60 \mathrm{~mm}$. $/ \mathrm{hr} .{ }^{\Phi}$ Five further blood cultures were sterile, no L.E. cells $\vec{\bullet}$ were found in films made from the peripheral blood, o and the serum proteins were normal (albumin $3.6 \mathrm{~g} /{ }^{\circ}$ $100 \mathrm{ml}$., globulin $2.49 \mathrm{~g} . / 100 \mathrm{ml}$.). Serum agglutination reactions, repeated on May 5 , showed a rise in titre $S$. typhimurium "H" from less than 40 to 320 ; three⿳亠二口 urine cultures and three stool cultures, however, gave no growth of this organism, and on May 23 serum $\mathbb{\perp}$ agglutination titres to $S$. typhimurium were again less $\overrightarrow{\vec{P}}$ than 40 .

On May 18 the first symptom of arthritis appeared, $\frac{3}{\sqrt{3}}$ the right ankle becoming swollen and painful. A smallo amount of fluid was aspirated, but culture was sterile. A course of chloramphenicol from May 18 to 25 produced no response and the ankle remained swollen and painful. Later in May, pain developed in the left 3 ankle and in both knees and some of the interphalangeat ${ }_{-}$. joints of the fingers became swollen and tender. Pro-을 gressive depression of the nasal bridge was noticed. The ears became softer with loss of the normal folds응 and collapse of the meatal orifices. The voice had $>$ become hoarse. Fig. 1 (opposite) shows the appearance을. at this time.

By May 31 the haemoglobin had dropped to $8 \cdot 5 \mathrm{~N}$ g./100 ml., the leucocyte count being $7,500 / \mathrm{c} . \mathrm{mm}$. with a normal differential count, and the erythrocyte sedimentation rate $63 \mathrm{~mm}$. $/ \mathrm{hr}$. The urine was reported as $\omega$ containing Bence-Jones protein on June 2, 3, and 4, but? the plasma proteins were again normal on June 2.0 Radiological examination of the skeleton and examina- $\bar{\Phi}$ tion of the sternal marrow (June 6) showed no evidence $\stackrel{?}{+}$ of myelomatosis. Cultures of the marrow were sterile.

At this stage she was seen by H.R.D., who consideredo that the condition could be accounted for by rheumatoid 
Fig. 1.-General appearance of patient on May 18, 1955.

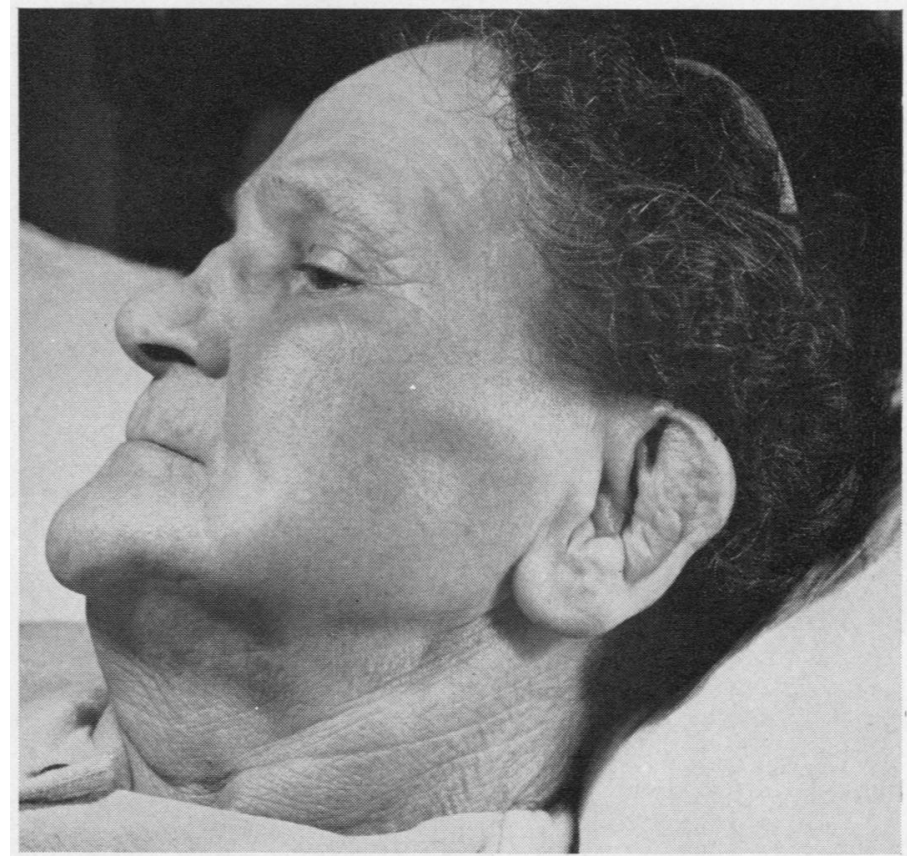

disease, but had never seen similar involvement of fibrocartilage in this condition. On June 8, therefore, treatment with sodium salicylate in full dosage was begun and the pyrexia, which had hitherto remained persistently between $99^{\circ}$ and $101^{\circ} \mathrm{F}$., showed an immediate drop to $99^{\circ} \mathrm{F}$. or under. The patient's condition began to improve, but by June 27 the haemoglobin had dropped to $7.3 \mathrm{~g} . / 100 \mathrm{ml}$. and the erythrocyte sedimentation rate had risen further to $70 \mathrm{~mm}$. $/ \mathrm{hr}$. She was therefore given a transfusion of two pints of blood and the haemoglobin had risen to $9.9 \mathrm{~g} . / 100 \mathrm{ml}$. by July 4. A further transfusion of three pints of blood was given on July 9 and on July 12 the haemoglobin was $12 \cdot 1 \mathrm{~g} . / 100 \mathrm{ml}$. and the erythrocyte sedimentation rate had fallen to $45 \mathrm{~mm}$./ hr. On July 22 the differential agglutination test (Rose-Waaler) was positive (16). Treatment with sodium salicylate was continued, but the ankles remained swollen and painful. On August 12 the patient was given $25 \mathrm{mg}$. ACTH in an intravenous saline drip transfusion over 24 hours; this produced considerable relief for 10 days, but then the knees and ankles again became painful. A second intravenous saline drip containing $25 \mathrm{mg}$. ACTH was given on August 24, with relief of symptoms over the next month. Pain returned on September 25 and she was given $20 \mathrm{mg}$. ACTH gel intramuscularly, with only transient relief. On October 1, a third intravenous ACTH drip was given with excellent effect. The pain and swelling in the ankles subsided and she was discharged to her home on October 19, 1955, taking aspirin $10 \mathrm{gr}$. four times daily. The haemoglobin on September 27 was $11.9 \mathrm{~g} . / 100 \mathrm{ml}$. and the erythrocyte sedimentation rate $50 \mathrm{~mm} . / \mathrm{hr}$.

On June 6, 1955, she had been seen by Dr. I. Martin-
Scott, consultant dermatologist to the West Herts Hospital Group, who commented as follows:

"I have never seen such a picture before. The ear condition seems to be due to swelling of cartilage rather than skin. The areas affected in her pyrexial syndrome are all developed from fibro-cartilage-larynx, ears, and nose."

He suggested biopsy of whole-ear thickness and this was done before discharge. It was reported on by Dr. C. Pike, consultant morbid anatomist to the West Herts Hospital Group, as follows:

"Cartilage of pinna with overlying corium and squamous epithelium bearing hairs and numerous sebaceous glands. At one end of the specimen the cartilage appears normal. At the other extremity it is thickened and broken up into irregular islands, separated by loose fibrous tissue, infiltrated by lymphocytes, plasma cells, and some neutrophils. The cartilage shows altered staining with loss of fuchsinophil fibrils, and thickening of fibres staining with elastica stains" (Fig. 2, overleaf).

Since discharge in 1955 , the patient has attended the out-patient clinic regularly. The appearance of her nose and ears has remained unchanged and her voice is still hoarse though less markedly so. The dose of aspirin was gradually reduced from December, 1956, and finally stopped in March, 1957, without any return of joint pain or swelling. The haemoglobin has varied from 12.7 to $14.6 \mathrm{~g} . / 100 \mathrm{ml}$. and the erythrocyte sedimentation rate from 15 to $39 \mathrm{~mm}$./hr. She was last seen by Mr. W. D. Doey in May, 1957, when the larynx appeared to be quite healthy, the vocal cords were healthy and mobile, and the laryngeal cartilage felt quite firm on palpation: no further changes were noticed in the appear- 


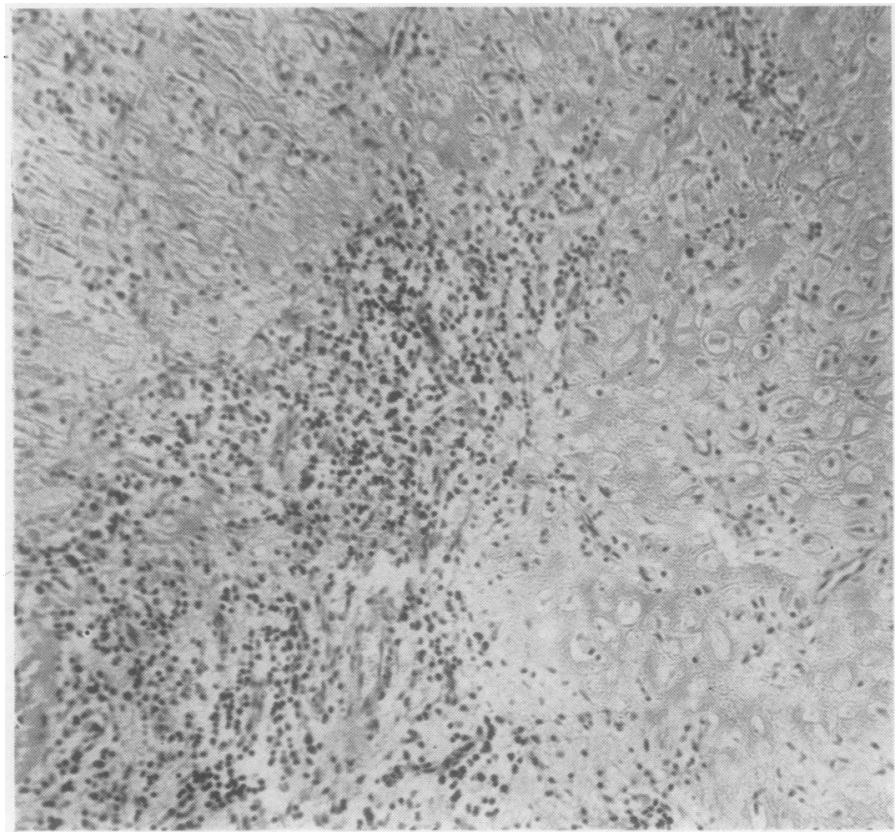

Fig. 2.-Biopsy of the ear, showing cartilage of the pinna broken up by vascular tissue infiltrated by lymphocytes, plasma cells, and some neutrophils: Haematoxylin and Van Gieson.

ance of the auricles, meatal orifices, or nasal septal cartilage.

During the same month, however, she was re-admitted suffering from coal-gas poisoning, having been found lying in front of a gas oven with the tap half on; although she admitted having been depressed for the preceding 2 weeks, she denied any suicidal intention and the episode may have been accidental. She made an uneventful recovery and has shown no further evidence of depression. At her last visit, on September 16, 1960, she was very well.

\section{Discussion}

This patient showed the typical combination of cartilaginous degeneration of the ears and nasal septum, leading to deformity, with laryngeal symptoms, respiratory infection, pyrexia, and arthritis. The cartilaginous changes preceded the arthritis, as in the patients described by Von Meyenburg (1936), Harders (1954), Bean, Drevets, and Chapman (1958), and Harwood (1958). But sometimes the order is reversed, as in the cases reported by Jaksch-Wartenhorst (1923), Gordon, Perlman, and Shechter (1948), Hilding (1952), Bober and Czarniecki (1955), and Rogers and Lansbury (1955). No evidence was found of involvement of the costal cartilages or the trachea, and no ocular symptoms occurred. Investigations, as in the previously reported cases, threw little light on the nature of the disease process; anaemia and a raised erythrocyte sedimentation rate during the active phase were of no specific significance and the temporary rise $\&$ n. the $S$. typhimurium agglutination titre was thought to be of diagnostic value. The presence $\overline{0}$. Tि Bence-Jones protein in the urine was a puzzling and unexplained finding; it has not been reported in anyo of the other published cases. There was certainly no other evidence of myelomatosis and the patient's favourable progress over the next 5 years is sufficient $\frac{0}{3}$ to exclude this condition. It is of course known that Bence-Jones protein can occur in other dis orders of bone and marrow, such as sarcoma of bone, metastatic bone tumours, senile osteomalacia, fibrocystic disease, lymphatic and myeloid leukaemia, $\overline{-}$ and polycythaemia (Geschickter and Copeland, 1928); it has also been recorded in patients withô carcinoma of the stomach and kidney and in a patient with prostatitis and inactive pulmonaryo tuberculosis (Bayrd and Heck, 1947). Moreover. $D$ it is known that anomalous serum protein patternso of the myeloma type may occasionally occur in patients with other diseases, particularly lymphoid reticulosis and macroglobulinaemia (Owen and 0 Rider, 1957). Abnormal serum proteins have also N been found in patients with haemolytic anaemia, malignant disease, and numerous other conditionso including "rheumatic" disease (Owen and Got, $\frac{\complement}{\Phi}$ 1960). Unfortunately facilities for electrophoretic $\stackrel{+}{-}$ examination of the serum proteins were not avail- $\square$ able to us in 1955, and although the albumin ando globulin fractions were quantitatively normal in our 
patient's serum, it is possible that electrophoresis might have revealed an abnormal pattern. The most interesting finding was the positive differential agglutination test, which has not been reported in any other case. We do not think that this can be regarded as conclusive evidence that this syndrome is a variant of rheumatoid disease, but it does suggest that there is some inter-relationship. Until we have a much clearer understanding of the real nature of the pathological process in rheumatoid disease and in the so-called collagen disorders, we feel that speculation along these lines is of little value.

The favourable response to ACTH in our patient is in keeping with other reports. Definite improvement with prednisone, with relapse on withdrawal, was observed by Bean, Drevets, and Chapman (1938), and by Pearson, Kline, and Newcomer (1960); some improvement after ACTH was reported by Bober and Czarniecki (1955), and by Klatskin and Katzenstein (1958). Harders (1956) also claimed a favourable response to steroid therapy.

A study of the previously recorded cases shows a remarkable uniformity in the fully-developed syndrome, though the order of involvement of different structures varies: patients may present with aural, laryngeal, respiratory, ocular, or articular symptoms, and are therefore liable to be seen initially in a relatively specialized department rather than by a general physician. The evolution of the complete syndrome may extend over several years. The prognosis is variable: the main danger is respiratory obstruction requiring tracheotomy (Von Meyenburg, 1936; Gordon, Perlman, and Shechter, 1948; Harders, 1954; Bober and Czarniecki, 1955), or causing death (Harwood, 1958; Klatskin and Katzenstein, 1958). If these disasters are avoided, the disease may become quiescent, though the deformities of the ears and nose do not alter. On the present evidence ACTH or steroids appear to be the treatment of choice.

\section{Summary}

A case of atrophic polychondritis, under observation for more than 5 years, is described; this is believed to be the first reported in Great Britain. The patient presented with degeneration of cartilage in the ears, nose, and respiratory tract; subsequently she developed polyarthritis, but there were no ocular manifestations, such as have been recorded in some previous cases.

A brief review of the literature is given.

The photomicrograph is reproduced by permission of Dr. C. Pike, to whom our thanks are due.

\section{REFERENCES}

Altherr, F. (1936). Virchows Arch. path. Anat., 297, 445. Bayrd, E. D., and Heck, F. J. (1947). J. Amer. med. Ass., 133, 147.

Bean, W. B. (1960). "VI International Congress of Internal Medicine. Handbook. Basel, 1960", p. 192.

—, Drevets, C. C., and Chapman, J. S. (1958). Medicine (Baltimore), 37, 353.

Bober, S., and Czarniecki, W. (1955). Schweiz. med. Wschr., 85, 448.

Geschickter, C. F., and Copeland, M. M. (1928). Arch. Surg. (Chicago), 16, 807.

Gill, R. J. (1960). "VI International Congress of Internal Medicine. Handbook. Basel, 1960", p. 193.

Gordon, E. J., Perlman, A. W., and Shechter, N. (1948). J. Bone Jt Surg., 30A, 944.

Harders, H. (1954). Schweiz. med. Wschr., 84, 712.

- (1956). Acta med. scand., 154, Suppl. 312, p. 442.

Harwood, T. R. (1958). A.M.A. Arch. Path., 65, 81.

Hilding, A. C. (1952). Arch. intern. Med., 89, 445.

Jaksch-Wartenhorst, R. (1923). Wien. Arch. inn. Med., 6, 93.

Klatskin, G., and Katzenstein, R. E. (1958). Resident Physician, 4, 75.

Owen, J. A. and Got, C. (1960). J. clin. Path., 13, 58. — and Rider, W. D. (1957). Ibid., 10, 373.

Pearson, C. M., Kline, H. M., and Newcomer, V. D. (1960). New Engl. J. Med., 263, 51.

Rogers, F. B., and Lansbury, J. (1955). Amer. J. med. -Sci.," 229," 55.

Meyenburg, H. von (1936). Schweiz. med. Wschr., $17,1239$.

\section{Polychondrite atrophique}

Avec présentation d'un cas

RÉSUMÉ

On décrit un cas de polychondrite atrophique, observé pendant plus de cinq ans; on croit que c'est le premier cas rapporté en Grande Bretagne. La maladie a commencé avec dégénérescence des cartilages des oreilles, du nez et des voies respiratoires; après cela la malade manifesta une polyarthrite, mais il n'y avait pas de symptômes oculaires du type décrit dans quelques autres cas. sujet.

On présente un brève revue de la littérature sur ce

\section{Policondritis atrófica}

Con la presentación de un caso

\section{SUMARIO}

Se presenta el que parece ser el primer caso descrito en Gran Bretaña, de policondritis atrófica, sometido a observación durante más de cinco años. La enfermedad comenzó con degeneración de los cartílagos de las orejas, nariz y tracto respiratorio; posteriormente la enferma desarrolló poliartritis, pero no se observaron manifestaciones oculares, del tipo descrito en algunos casos anteriores.

Se realiza una breve revisión de la literatura sobre el tema. 